\title{
The Defining Moment
}

Sometimes, it takes only one event to make us question our existence and alter the course of our lives. The editors of the Canadian Journal of Nursing Leadership asked three nursing leaders what was their defining moment and what single event set them on their current path.

Rob Calnan, RN, BScn, MEd

Rob Calnan is President of the Canadian Nurses Association (CNA). Mr. Calnan is the nurse manager for burns, plastics, complex wounds, eyes, ears, nose and throat, general surgery, abdominal/thoracic surgery and urology at Royal Jubilee Hospital in Victoria, British Columbia. He received the Queen's Golden Jubilee Medal in 2004 for his contribution to healthcare and was one of four Canadian nurses on an International Council of Nurses delegation to the World Health Assembly. He is an outspoken nursing advocate who writes and speaks about the value of nursing and the future of healthcare in Canada.

There is no life changing event that compares to the first trip I took to Haiti to work, and to bring our infant son home. Arriving in Haiti in 1995 was an eye-opening experience. I left the peace and tranquility of Canada and landed in a country under military control as a dictatorship fell and the installation of a new democratic government ensued. Flying into an airport surrounded by army tanks, barbed wire and the everpresent army personnel made me realize the freedoms that I take for granted in Canada. Driving to the orphanage where I would meet my son, I saw the shacks that people call home.

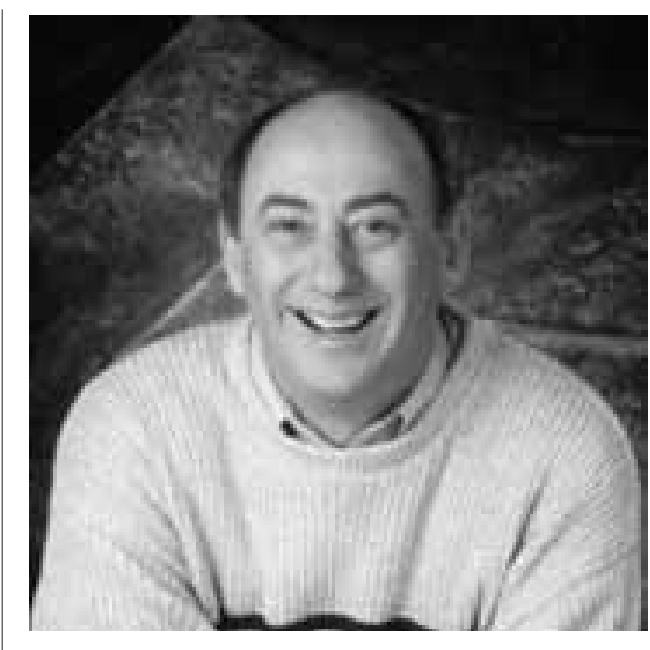

“... it is the common values of equity and justice that Canadians hold that lead to the founding of the Canada Health Act."

In Haiti, and other developing countries, people are worried about food, housing, water - the basics and essentials to life. Babies have swollen bellies and their black hair is reddened because of malnutrition. People are dying of diseases that, in Canada and elsewhere, are prevented thanks to immunization programs. More than ever I saw the true meaning of the determinants of health and for the first time, truly understood Maslov's hierarchy of needs.

I realize that it is the common values of equity and justice that Canadians hold that lead to the founding of the 
Canada Health Act and a publicly funded not-for-profit healthcare system where all Canadians have access to healthcare services. My experiences in Haiti have made me recognize that the best health outcomes aren't based solely on the most money spent on health itself, but on an egalitarian society that invests in the true determinants of health-disease prevention through immunization and education, affordable housing, breakfast and lunch programs in schools, educational opportunities for all, supporting its healthcare work force, fresh water and clean air.

Today, as President of the Canadian Nurses Association, I find myself being presented with reports from Senator Kirby, Commissioner Romanow, the Canadian Nursing Advisory Committee and on SARS. I recognize that for all the faults outlined in these reports, Canadians are truly committed to sustaining a social justice system and to finding solutions to resolve these issues not only in our country, but abroad. I am proud to count myself among these citizens.

Michael J. Villeneuve, RN, BScN, MS Michael Villeneuve is Senior Nursing Policy Consultant in the Office of Nursing Policy at Health Canada. With 25 years of progressive experience in the healthcare system, Mr. Villeneuve has held positions as a nursing attendant, staff nurse, instructor, lecturer and clinical nurse specialist in neurosurgery and trauma. On the management side, Mr. Villeneuve has worked for Health Canada in charge of an outpost nursing station in Northern Manitoba, and

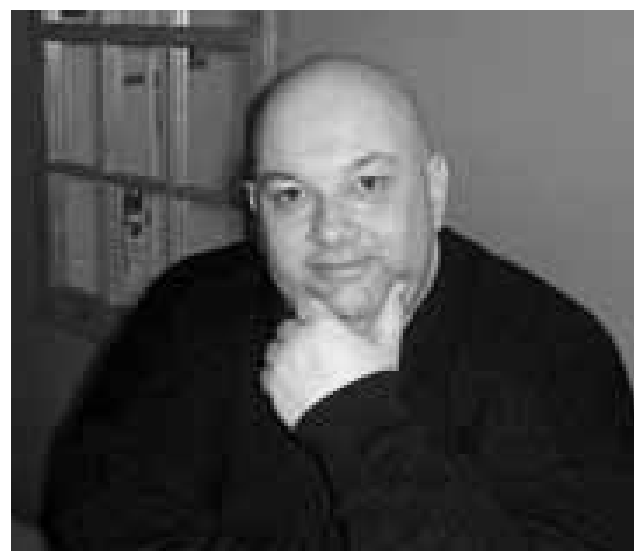

"You have no right to judge or hurt any other person."

was Patient Care Manager of the Neurosurgical Intensive Care and Neuro/Trauma Units at Sunnybrook \& Women's Health Sciences Centre in Toronto. During 2003 he represented Health Canada at the Organization for Economic Cooperation and Development. Mr. Villeneuve has published and presented widely on a variety of nursing and health policy topics. He maintains strong interests in diversity and social justice issues.

I suppose I was in many ways a stereotypical ' 60 s child. The earliest memory I can clearly date was November 22, 1963. "Camelot" had suddenly collapsed into a nightmare before our eyes, and it was the first time I can remember seeing my mother cry. I was four.

The following decade is a blur of images I mostly didn't understand. I was confused by graphic images of police turning water hoses on black people, the National Guard shooting students at Kent State, protest marches, assassinations and the FLQ crisis here 
at home. I came out of that period feeling a very personal need to do "something" about human rights.

The seminal memory in my emerging racial consciousness was a much more personal moment on the day I made some casual racial slur as a child. My conservative, Caucasian mother took hold of me and, leaving no room for misunderstanding, instructed me that the colour of my skin was nothing but an accident of birth. "You didn't earn that. You are no better than anybody else on this earth. You have no right to judge or hurt any other person.” That lesson, her voice and her disappointment still ring in my ears today. That was my first real experience with the notion of "walking the talk."

Years later, Maya Angelou's, "I Know Why the Caged Bird Sings" took years of emotion, fear and confusion, and framed it in words that helped it all make sense. Her simple story of a poor black girl took the political to the personal for me. She broke down the concept of racism and made it real for me, helping me to understand that while I am not responsible for whatever historic events brought us to this place, I am responsible not to stand by when any people are suffering as a result of them. That book changed my world. I still return to it every few years, always finding new messages in its beautiful language and poignant story.

David Gregory, RN, BScN, MN, PhD David Gregory is Professor and Dean, Faculty of Nursing, University of Manitoba. $\mathrm{He}$ is also Professor in the College of

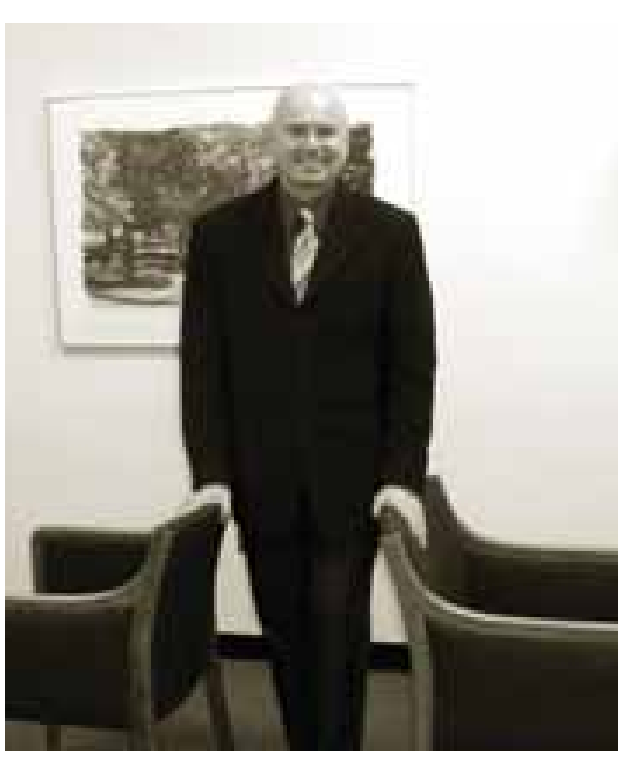

\section{"It was a heady, challenging and humbling experience."}

Nursing, University of Tennessee, Memphis. Dr. Gregory's research interests include suffering/palliative care, aboriginal health issues and qualitative research methodology. He has published widely on a variety of nursing topics.

He was recently awarded the Award for Excellence in Professional Nursing Administration by the College of Registered Nurses of Manitoba. His administrative leadership has also been acknowledged by the Canadian Association of Schools of Nursing and he was presented the Association's Award for Academic Administrative Excellence in 2001.

It wasn't planned. A high school guidance counselor, in retrospect a wise woman, suggested nursing as my chosen profession. It was with resistance and great self-doubt that I enrolled at the University of Ottawa. 
My desire to care for others was born out of the death of my mother when I was 16 , four years before starting my baccalaureate degree. My nursing professors lit the education "fire in my belly." Their words convinced me to pursue a doctorate - an impossible message to receive as an undergraduate student.

It was at the College of Nursing, University of Arizona

(Tucson) that the world opened up to me and me to it. Not a cliché but the reality of encountering an explosion of knowledge within and beyond nursing. I wanted a complete change from my surroundings in Winnipeg. Tucson (the University of Arizona) offered me what I was looking for: desert climate and vegetation, mountain ranges and a chance to explore a "new world." Also, one of my colleagues, Dr. Linda Kristjanson, completed her $\mathrm{PhD}$ there

and she highly recommended the College of Nursing and its $\mathrm{PhD}$

Program. It met all my expectations and more.

The PhD moved me from dichotomous understanding, past uncertainty and into knowing the world as a complex and mysterious place. It was a heady, challenging and humbling experience. It changed me profoundly. I am grateful to my nursing and anthropology professors and to my fellow students. 